\title{
Estudo do processo de fabricação de tubos flexíveis de aço inoxidável duplex UNS 32304 utilizados na indústria de petróleo e gás
}

\author{
(Study of the manufacturing process of UNS 32304 flexible pipes for the oil and gas industry)
}

\author{
Ida Paula Gusmão de Oliveiral, Temístocles de Sousa Luz ${ }^{1}$ \\ ${ }^{1}$ Universidade Federal do Espírito Santo, Departamento de Engenharia Mecânica, Vitória, ES, Brasil,ida.gusmao@gmail.com, \\ temistocles.luz@ufes.br
}

\begin{abstract}
Resumo
A principal característica dos aços inoxidáveis duplex é o equilibrio entre as fases austenita e ferrita, que garantem ao material melhores índices de resistências à corrosão e mecânica. No entanto, durante o processo de soldagem, ocorrem modificações estruturais, principalmente no balanço destas fases. Este desbalanceamento, em função dos níveis de solicitações mecânicas, pode levar tais regiões soldadas a colapso. No intuito de minimizar o desequilíbrio das fases na região soldada, diversas técnicas são utilizadas, tais como inserção de metal de adição com elementos austenitizantes, uso de gás de proteção com nitrogênio ou, em outros casos, controle pós soldagem. Buscou-se identificar o verdadeiro efeito dos parâmetros de soldagem e do tratamento térmico especificado pela literatura em situações de campo. Através de uma avaliação temporal, observando uma linha de produção de tubulação flexível de aço inoxidável duplex UNS 32304 durante três anos, utilizando-se de procedimentos convencionais de soldagem com e sem a utilização de tratamento térmico foram observadas as falhas por fratura na zona termicamente afetada (ZTA).Foi utilizado um indutor localizado para o tratamento térmico, gerando um intenso fluxo de calor que promoveu temperaturas da ordem de $1000{ }^{\circ} \mathrm{C}$ a altíssimas taxas de subida e descida, conforme estabelecem algumas literaturas.
\end{abstract}

Palavras-chave: Soldagem, aço inoxidável duplex, tubo flexível.

\begin{abstract}
The main characteristic of duplex stainless steels is the balance between ferrite and austenite phases, wich ensures to such material the best levels of corrosion and mechanical resistance. However, during the welding process, structural modifications occur, especially with regard to the balance of these phases. This imbalance, depending on the levels of mechanical stress, may lead welded regions to collapse. In order to minimize the imbalance of the phases in the welded steel, several techniques are used, such as the insertion of filler metal with austenite formers, the use of shielding gas with nitrogen or, in other cases, the post weld control. It was tried to identify the true effect of welding parameters and heat treatment specified by the literature in field situations. Through an temporal evaluation, watching a production line of flexible pipes of UNS 32304 duplex stainless steel during three years, using conventional welding procedures with and without the use of heat treatment, failures were observed by a fracture in the heat affected zone (HZA). It was used a local inductor to the heat treatment, generating an intense heat flow that caused temperatures of about $1000{ }^{\circ} \mathrm{C}$ at very high rate of ascent and descent, as set for some literatures.
\end{abstract}

Key-words: Welding; duplex stainless steel; flexible pipe.

\section{Introdução}

O tubos flexíveis são dutos utilizados em estruturas marítimas para o transporte de fluidos e/ou instrumentalizar sistemas em platafomas marítimas. São estruturas complexas com múltiplas camadas que utilizam armaduras helicoidais de fios ou fitas, combinadas com camadas concêntricas de polímeros, têxteis, fitas adesivas e lubrificantes para produção de uma estrutura compatível, capaz de suportar consideráveis cargas estruturais, bem como as pressões internas e externas. O número e o tipo de

(Recebido em 01/11/2011; Texto final em 24/08/2012). camadas de componentes depende dos requisitos de concepção específica [1].

No caso do transporte de fluidos, as principais barreiras estanqueis são termoplásticas e aço, sendo este último, composto por fios e chapas resistentes à corrosão. A camada interna, que tem contato com o fluido corrosivo composto de óleo e água salina, devem ser confeccionadas em aço resistente à corrosão. Pra tanto, em sua fabricação são utilizadas fitas metálicas de aços inoxidáveis de diversas classes, dependendo da severidade do fluido a ser transportado, o que no caso do petróleo, dependerá do tipo de poço produtivo (aspectos corrosivos do óleo retirado desse poço)[2].

Devido ao aumento da utilização dos tubos flexíveis no ambiente marinho, há uma crescente investigação sobre o comportamento destas estruturas flexíveis. Embora jás se tenha 
evoluído de forma importante quanto a uma configuração otimizada dessas estruturas, durante sua fabricação, alguns pontos ainda se configuram como obstáculos, necessitando ainda de estudos Um desses pontos é a soldagem. Em função da complexidade das estruturas produzidas, algumas regiões da união gerada podem ser locaispotenciais de problemas estruturais. Isso se torna mais grave quanto maior é a complexidade da liga a ser soldada $[1,2]$.

Com a crescente demanda desse tipo de tubulação, devido ao aumento da produção de petróleo e gás, mais ligas mais específicas são utilizadas, em função de suas carcterísticas de resistências aos processos de degradação que ocorrem de forma acentuada nos poços de petróleo em produção no Brasil. Assim, os aços inoxidáveis duplex, em função de suas características, tem sido cada vez mais solicitados na configuração dessas tubulações [2]. Em comparação aos aços inoxidáveis puramente ferríticos, os aços inoxidáveis duplex oferecem melhor resistência à corrosão além de uma maior resistência mecânica, quando, também comparados às grades austeníticas puras. Assim, essa classe de aço inoxidável tem sido amplamente utilizada nas indústrias químicas e petroquímicas e/ou equipamentos submetidos a ambientes marítimos, geralmente em situações que exigem uma combinação de resistência mecânica e resistência à corrosão [3 $-8]$.

O processo de fabricação desses dutos são estabelecidos em sequências de conformação e soldagens. Como mostrado na Figura 1, diversas camadas compõem a estrutura do tubo flexível. A estrutura inical, composta de aço inoxidável duplex, em grande parte das tubulações flexíveis, é dotada de um sistema de encaixe de uma "fita" previamente conformada de maneira a permitir esse engate e montagem dessa "espiral". Para o processo de "espiralagem" manter a sua continuidade, fitas do aço em questão são soldadas umas às outras mantendo um sistema contínuo até a obtenção da esxtensão de tubo pretendida. Em função da severidade do processo de conformação, as juntas devem apresentar boas características mecânicas. Essa conformação consta da formatação em "S" das "fitas" de aços inoxidável duplex, para um encaixe sequencial e "espiralagem", concretizando-se dessa forma o que se conhece como tubo flexível. Além de toda a solicitação durante o processo fabril dessas tubulações, em campo, estas estão sujeitas a diversos esforços, dentre os quais se pode citar os esforços trativos de todo o conjunto, além dos esforços de compressão que podem ser experimentados durante a instalação em águas profundas (efeito tampão devido à alta pressão hidrostática) ou em situações extremas, como quando a unidade flutuante opera em condições de baixo ângulo superior e está sujeito a movimentos bruscos. Em tais condições, um fenômeno de instabilidade pode ocorrer e os fios de armadura podem ter grandes deslocamentos laterais ou radiais, sendo este último geralmente citado como "bird caging" por causa da topologia assumida dos fios [9]. Todo esse sistema complexo de carregamentos leva a uma preocupação maior com relação a qualidade dos materiais em utilização.

Em uma avaliação de um processo produtivo dessas tubulações, verifica-se que em um ano são produzidos mais de $50 \mathrm{~km}$ de tubulações utilizando o aço inoxidável duplex UNS S32304. Para cada tubulação fabricada, dependendo do diâmetro da tubulação, várias soldagens são realizadas para dar continuidade do processo de conformação dessas tubulações. Para tais uniões são utilizadas soldagens autógenas com o processo TIG (“Tungsten Inert Gas").

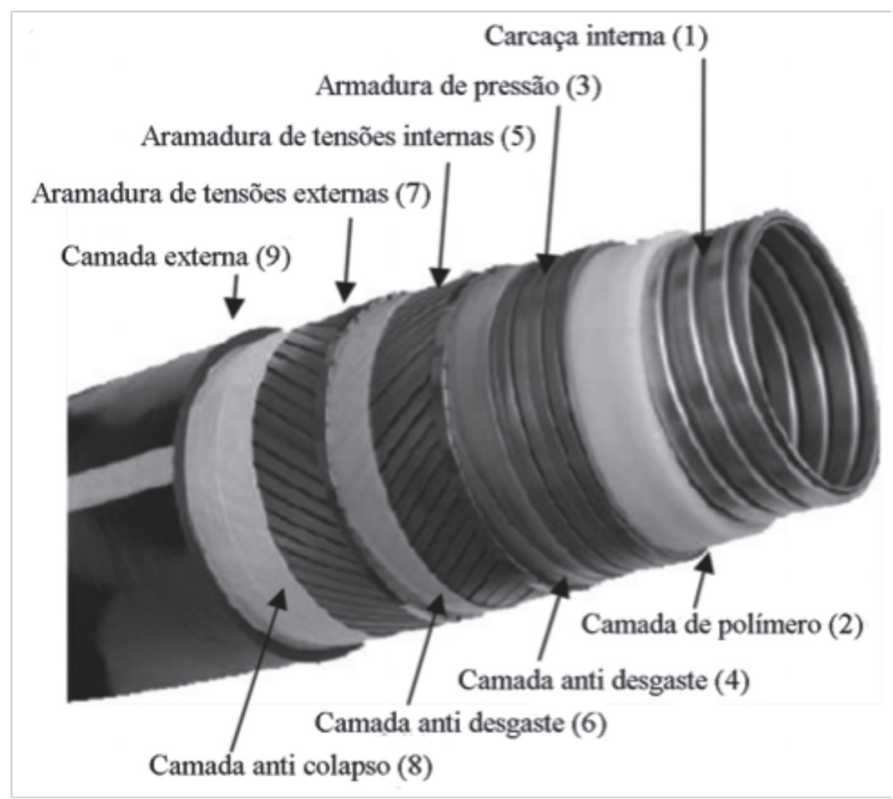

Figura 1. Tubo flexível típico [9]

A aplicação dos aços inoxidáveis duplex no setor petroquímico conduziu à elaboração de critérios de qualidade para esse tipo de aço e às juntas soldadas, tanto no que se refere ao macro e à microestrutura, propriedades mecânicas e resistência de corrosão. Uma atenção especial foi dada à fração da ferrita-austenita, à presença de carbonetos nos contornos de grão e às precipitações de fases intermetálicas no metal de solda e zona termicamente afetada (ZTA). A definição desses critérios exige um controle apropriado dos processos de transformação que envolvem tais materiais, principalmente no que se refere aos processos de soldagem, devido aos ciclos de calor que tais processos incidem sobre o metal durante a execução das soldas [3].

Em relação a fração de austenita e ferrita, verifica-se, segundo a literatura corrente, que o ajuste do balanço ferrita/austenita, durante a fabricação desses aços, é estabelecido à temperaturas na ordem de $1000{ }^{\circ} \mathrm{C}[10]$, sendo tal balanço situado em torno de $50 \%$. A literatura mostra que o ciclo térmico de soldagem tem uma grande influência nesse balanço, verificando-se que quanto maior o fluxo de calor no processo de resfriamento, maior o teor de ferrita, causando assim, um maior desequilíbrio entre as fases [11]. Assim, diversas literaturas apontam para um tratamento térmico pós soldagem na ordem de $1050{ }^{\circ} \mathrm{C}[2,12]$. Acredita-se que devido a tal tratamento, muitos dos problemas sejam minimizados, como pode ser observado na Figura 3, onde se verifica o nível de temperatura de estabilidade das fases intermetálicas e de transformação $a \rightarrow \gamma$. 


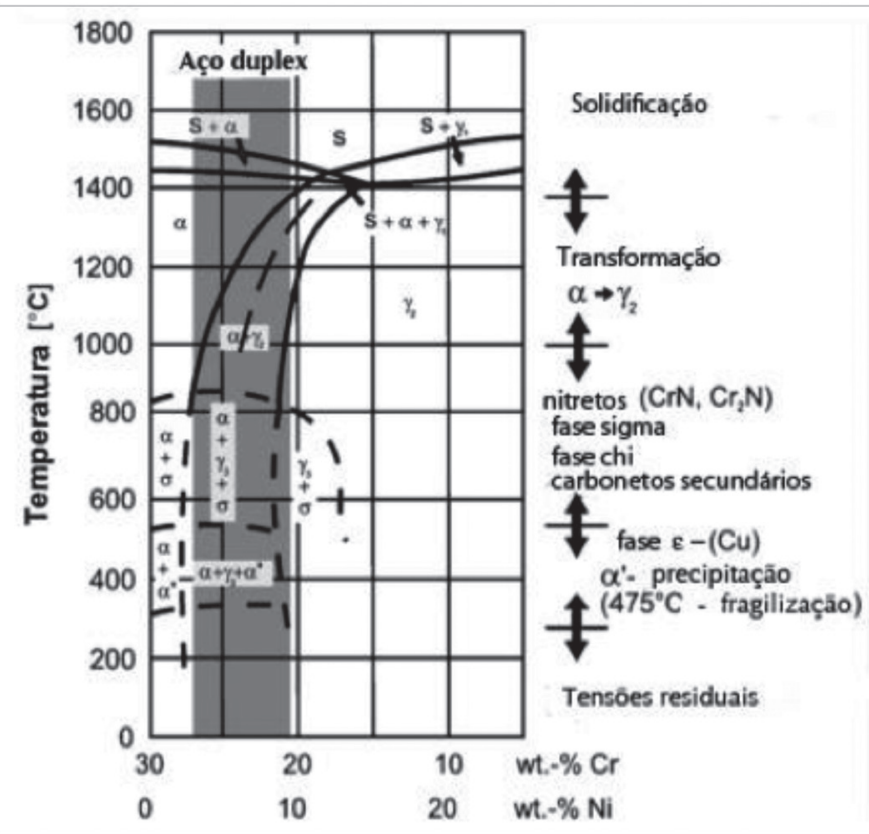

Figura 2. Diagrama de fases pseudo-binario $\mathrm{Fe}-\mathrm{Cr}-\mathrm{Ni}$ na secção de $70 \% \mathrm{Fe}[13]$.
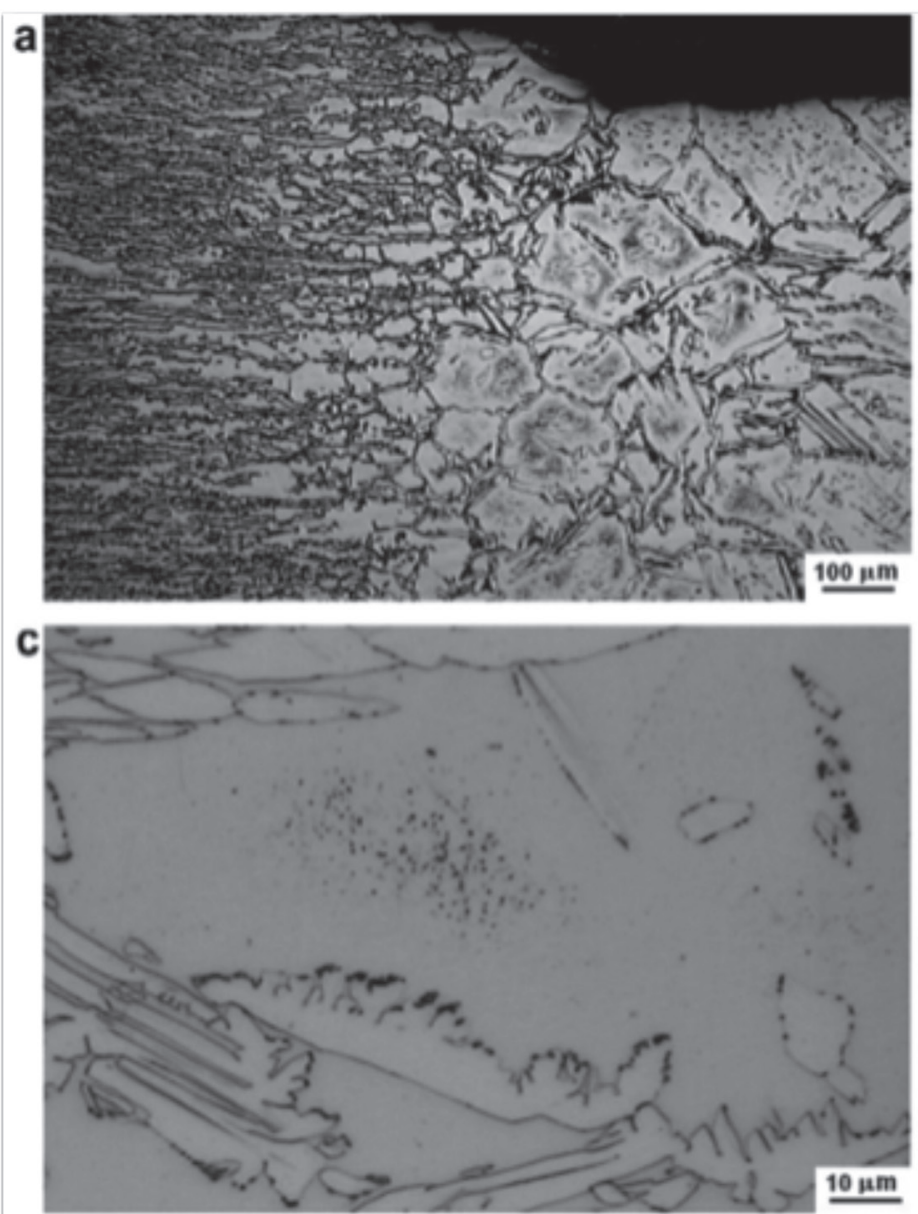

A Figura 2 mostra entre outros fatores, a precipitação de fases intermetálicas, muito característica nesses aços. A classe de aços UNS 32304, em sua maioria está livre da precipitação de fases como a sigma e chi. No entanto, diversos trabalhos apontam para a precipitação dos nitretos nos aços como um todo [13-18]. Em uma avaliação da fratura em uma solda de tubulação flexível confeccionada com o aço UNS 32304, durante a conformação mecânica, verificou-se que a microestrutura da região próxima à zona de fusão, para a soldagem autógena com o processo TIG, foi composta por $28,4 \%$ de austenita. O excesso de ferrita causou uma precipitação intensa $\mathrm{Cr}_{2} \mathrm{~N}$ dentro dos grãos de ferrita e também nas interfaces da ferrita e austenita (Figura 3). Esta microestrutura não-balanceada contendo partículas $\mathrm{Cr}_{2} \mathrm{~N}$ tem menor ductilidade e tenacidade [16], o que foi determinante para as trincas observadas [2].

Em virtude da grande demanda de tais tubulações torna-se premente uma avaliação dos efeitos do processo de soldagem, bem como do material sobre as características da união após o ciclo térmico e tratamentos térmicos após a soldagem. Com isso objetiva-se avaliar o efeito do tratamento térmico, sugerido pela literatura, e do tipo de material, sobre à qualidade da união após o processo de conformação mecânica, em uma linha de produção de tubulações de diversos diâmetros, confecionados em aço inoxidável duplex da classe UNS 32304.
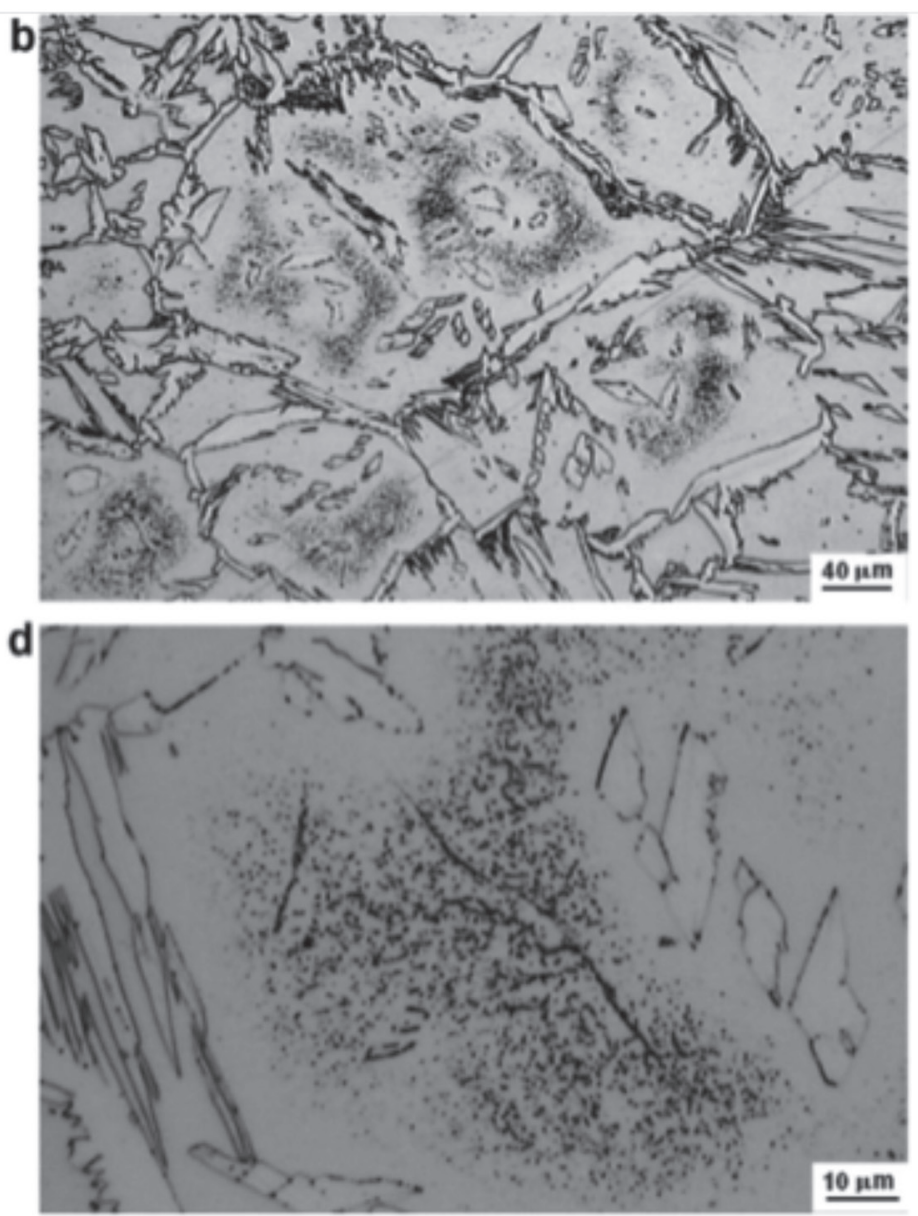

Figura 3. Região da solda para o aço inoxidável duplex UNS 32304. Ataque eletrolítico com uma solução de $10 \%$ de ácido oxálico (7 $\mathrm{V}-30 \mathrm{~s})[2]$. 


\section{Materiais e Métodos}

Para esse estudo foram observados durante os anos de 2008, 2009 e 2010, a linha de produção de tubos flexíveis, particularizando a utilização o aço inoxidável duplex UNS S32304. Durante tal período foi observada a fabricação dessas tubulações em diversos diâmetros nominais - 4" (100 mm) a $10 "$ (250 mm). Em cada um desses diâmetros houveram a utilização de quatro bitolas (espessuras) de fitas metálicas (1,0mm; 1,2mm; 1,5mm e 1,8mm). Foram observados ainda 0 material de dois fornecedores distintos. Para todas as condições, foram estabelecidas soldagens sem tratamentos térmicos pós sodagem (STT) bem como o tratamento térmico (TT) sugerido pela literatura $\left(1050{ }^{\circ} \mathrm{C}\right)$. Tais tratamentos térmicos foram etabelecidos através de um sitema indutivo o qual possibilita a obtenção de $1050^{\circ} \mathrm{C}$ em um tempo de 10 segundos. Através da Figura 4 é retratada a montagem do sistema de tratamento térmico "in situ" para a chapa de 1,8 mm. Por meio de um sensor térmico se controla o tempo de incidência da temperatura. $\mathrm{O}$ resfriamento das soldas é estabelecido ao tempo mas com as extremidades fixadas a suportes mantidos a temperaturas de aproximadamente $20^{\circ} \mathrm{C}$ (Figura 4 ).

Foram observadas pelo menos 4000 soldas ao longo de mais de $100 \mathrm{~km}$ de tubulações, sendo constatadas 97 trincas após o "perfilamento" da fita soldada, através de inspeção visual. Para tal avaliação foi definido o índice de eficiência de sodagem, o qual se baseia na relação entre a quantidade de soldagens realizadas em uma corrida pela quantidade de trincas após essas soldagens. Assim, para todo o processo observado, verificou-se uma eficiência de soldagem na ordem de 97,6\%. Para tal avaliação utilizou-se da análise de variância (ANOVA) utilizando a de 2,5\% (nível de significância).

A composição química do metal de base pode ser observada na Tabela 1. As soldagens foram todas realizadas em um único passe, em uma junta de topo, sem a utilização de metal de adição através do processo TIG pulsado com um período de pulso balanceado.Para cada bitola de fita utilizada foi estabelecida um nível de energia imposta (desconsiderando o rendimento do processo). Assim, através de um processo de qualificacão de equipamento para cada tipo de soldagem foram estabelecidos os seguintes níveis de energia impostas: para as bitolas de 1,0 mm e 1,2 mm foi utilizada o nível de energia de 1,25 kJ/ $\mathrm{mm}$; para a bitola de 1,5 utilizou-se $1,65 \mathrm{~kJ} / \mathrm{mm}$ e para bitola de 1,8 utilizou-se a energia de $2,00 \mathrm{~kJ} / \mathrm{mm}$. Todas as soldagens foram estabelecidas na posição plana, em uma junta de topo, utilizando uma distância média do eletrodo peça na ordem de $3 \mathrm{~mm}$. Foi utilizado como gás de proteção o argônio contendo $2 \%$ de nitrogênio, tanto na proteção da poça fundida quanto na raiz, através da utilização do gás de purga. Tal procedimento foi seguido, baseado na literatura que sugere a inserção de $\mathrm{N}_{2}$ no gás de proteção com o intuito de manter o balanço microestrutural (austenita e ferrita) o mais próximo da equidade [2, 4, 5, 12].

São apresentados em sequencia exemplos de não conformidades que ocorreram durante o período de estudo, considerando-se diferentes fornecedores, espessuras de fita e diâmetros da tubulação. É notado que em todas as condições as trincas ocorrem após a conformação mecânica ou durante
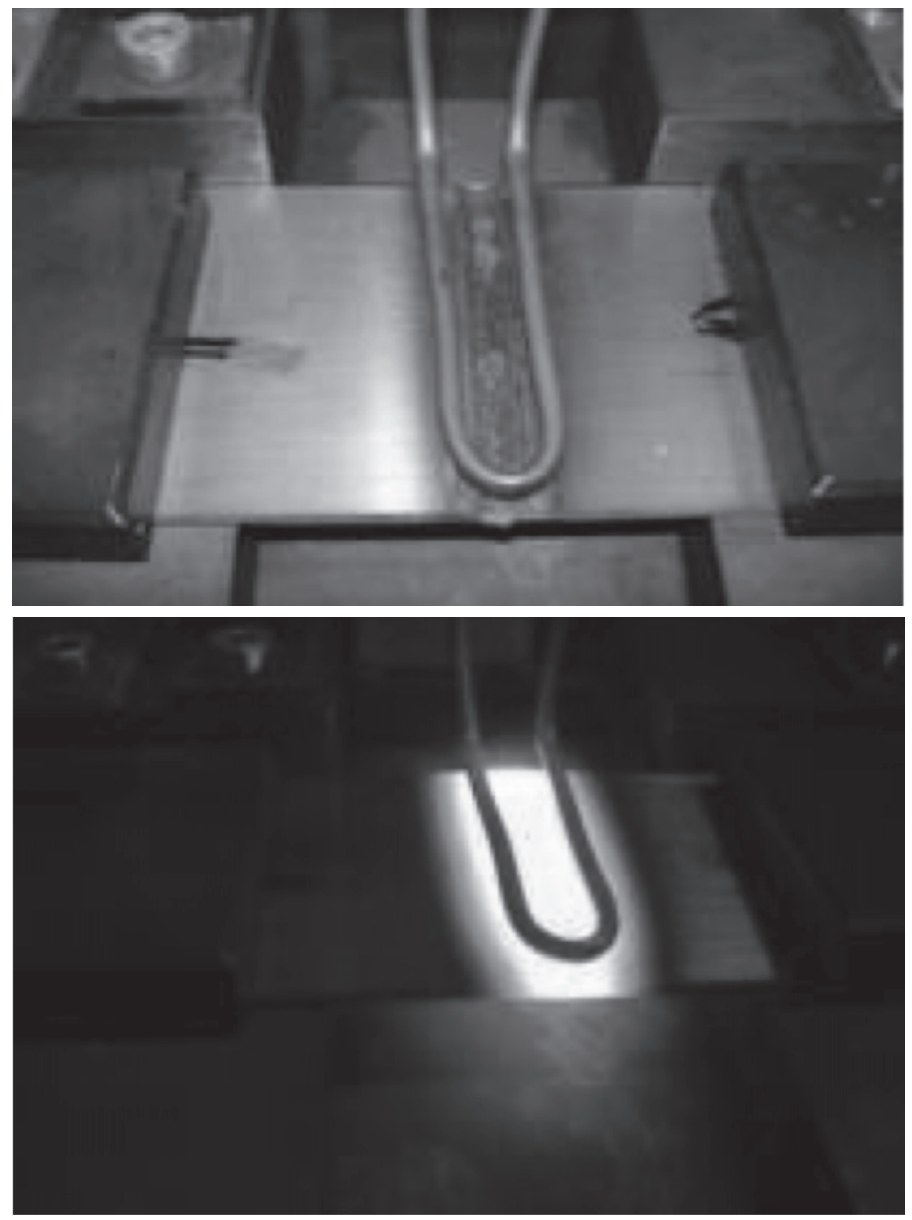

Figura 4. Seqüência de tratamento térmico.

a mesma. Verifica-se ainda, que as trincas, quando ocorrem, posicionam-se na região interfacial da zona fundida e do metal de base (Figura 5). Como foi mostrado na literatura [2], a qual utilizou-se do material mostrado na Figura 5a, as trincas para esse material seriam resultado de um sistema de precipitação, principalmente, de $\mathrm{Cr}_{2} \mathrm{~N}$, o qual aconteceria preferencialmente na ZTA. Foram verificados tais eventos tanto para soldagens sem tratamento térmico, como para soldagens utilizando o tratamento térmico pós soldagem.

No entanto, em uma observação mais criteriosa, verificase que existe certa distinção entre os dois materiais utilizados quando se observa o índice de eficiência de soldagem (Tabela 4). Com a realização de uma análise de variância dos resultados, verifica-se que o Material 1 é mais susceptível a ocorrência do fenômeno que o Material 2. A Figura 6a retrata esse efeito. Verifica-se que a variação é bem pequena em termos percentuais, no entanto, em campo, tal ocorrência gera um transtorno muito grande no processo produtivo, gerando grandes paradas para se sanar o problema gerado, havendo perdas consideráveis de material e tempo. O mercado anseia que tal índice seja o maior possível, esperando-se algo superior a 98\%. Assim, no que tange à ocorrência das trincas no processo de conformação verificase que o Material 2, cujos valores de Ni e Mo são menores, a princípio respondem melhor ao processo de união seguido de conformação mecânica. 
Tabela 1. Composição química do material de base.

\begin{tabular}{|c|c|c|c|c|c|c|c|c|c|c|}
\hline \multirow{2}{*}{ Tipo } & \multicolumn{10}{|c|}{ Composição (\%) } \\
\cline { 2 - 12 } & $\mathrm{C}$ & $\mathrm{Cu}$ & $\mathrm{Si}$ & $\mathrm{Mn}$ & $\mathrm{Cr}$ & $\mathrm{Mo}$ & $\mathrm{Ni}$ & $\mathrm{N}(\mathrm{ppm})$ & $\mathrm{S}$ & $\mathrm{P}$ \\
\hline Material 1 & 0,019 & 0,286 & 0,698 & 1,438 & 22,494 & 0,273 & 4,966 & 0,096 & 0,001 & 0,025 \\
\hline Material 2 & 0,024 & 0,433 & 0,295 & 1,412 & 22,252 & 0,164 & 3,617 & 0,122 & 0,001 & 0,029 \\
\hline
\end{tabular}

\section{Resultados e Discussão}

As Tabelas 2 e 3 apresentam os dados apurados durante o período de avaliação da produção das tubulações flexíveis utilizando o aço inoxidável duplex da classe UNS S32304.

Tabela 2. Resultados observados para a soldagem com o Material 1.

\begin{tabular}{|c|c|c|c|c|c|c|c|}
\hline Diâmetro (pol) & Espessura (mm) & Energia $(\mathrm{kJ} / \mathbf{m m})$ & Tratamento & Extensão (m) & Soldas & Trincas & Eficiência \\
\hline 4 & 1,0 & 1,25 & $\mathrm{TT}$ & 4795 & 90 & 0 & $100 \%$ \\
\hline 4 & 1,0 & 1,25 & STT & 2200 & 31 & 0 & $100 \%$ \\
\hline 4 & 1,2 & 1,25 & $\mathrm{TT}$ & 199 & 35 & 0 & $100 \%$ \\
\hline 4 & 1,2 & 1,25 & STT & 3000 & 51 & 0 & $100 \%$ \\
\hline 4 & 1,2 & 1,25 & $\mathrm{TT}$ & 2900 & 63 & 0 & $100 \%$ \\
\hline 4 & 1,2 & 1,25 & $\mathrm{TT}$ & 3000 & 52 & 4 & $92 \%$ \\
\hline 6 & 1,5 & 1,65 & STT & 2000 & 60 & 5 & $92 \%$ \\
\hline 6 & 1,5 & 1,65 & STT & 1920 & 54 & 6 & $89 \%$ \\
\hline 6 & 1,5 & 1,65 & TT & 725 & 17 & 2 & $88 \%$ \\
\hline 8 & 1,5 & 1,65 & STT & 1600 & 74 & 1 & $99 \%$ \\
\hline 8 & 1,5 & 1,65 & STT & 1600 & 48 & 2 & $96 \%$ \\
\hline 8 & 1,8 & 2,00 & STT & 400 & 15 & 1 & $93 \%$ \\
\hline 8 & 1,8 & 2,00 & STT & 965 & 46 & 6 & $87 \%$ \\
\hline 8 & 1,8 & 2,00 & STT & 885 & 45 & 0 & $100 \%$ \\
\hline 8 & 1,8 & 2,00 & STT & 1600 & 65 & 4 & $94 \%$ \\
\hline 8 & 1,8 & 2,00 & STT & 735 & 24 & 0 & $100 \%$ \\
\hline 8 & 1,8 & 2,00 & $\mathrm{TT}$ & 1660 & 54 & 2 & $96 \%$ \\
\hline 8 & 1,8 & 2,00 & $\mathrm{TT}$ & 1650 & 61 & 1 & $98 \%$ \\
\hline 8 & 1,8 & 2,00 & $\mathrm{TT}$ & 1310 & 42 & 2 & $95 \%$ \\
\hline 8 & 1,8 & 2,00 & $\mathrm{TT}$ & 1900 & 60 & 1 & $98 \%$ \\
\hline 8 & 1,8 & 2,00 & $\mathrm{TT}$ & 1100 & 47 & 0 & $100 \%$ \\
\hline 8 & 1,8 & 2,00 & $\mathrm{TT}$ & 1290 & 50 & 1 & $98 \%$ \\
\hline 10 & 1,8 & 2,00 & STT & 718 & 45 & 0 & $100 \%$ \\
\hline 10 & 1,8 & 2,00 & STT & 687 & 47 & 0 & $100 \%$ \\
\hline 10 & 1,8 & 2,00 & STT & 686 & 49 & 1 & $98 \%$ \\
\hline
\end{tabular}


Tabela 3. Resultados observados para a soldagem com o Material 2.

\begin{tabular}{|c|c|c|c|c|c|c|c|}
\hline Diâmetro (pol) & Espessura (mm) & Energia $(\mathrm{kJ} / \mathrm{mm})$ & Tratamento & Extensão (m) & Soldas & Trincas & Eficiência \\
\hline 4 & 1,0 & 1,25 & TT & 4720 & 109 & 1 & $99 \%$ \\
\hline 4 & 1,0 & 1,25 & STT & 2200 & 43 & 2 & $95 \%$ \\
\hline 4 & 1,0 & 1,25 & TT & 2542 & 114 & 0 & $100 \%$ \\
\hline 4 & 1,2 & 1,25 & STT & 4490 & 110 & 0 & $100 \%$ \\
\hline 4 & 1,2 & 1,25 & TT & 1300 & 61 & 0 & $100 \%$ \\
\hline 4 & 1,2 & 1,25 & TT & 2900 & 74 & 0 & $100 \%$ \\
\hline 6 & 1,5 & 1,65 & STT & 1000 & 53 & 2 & $96 \%$ \\
\hline 6 & 1,5 & 1,65 & STT & 1350 & 71 & 3 & $96 \%$ \\
\hline 6 & 1,5 & 1,65 & STT & 1000 & 34 & 2 & $94 \%$ \\
\hline 6 & 1,5 & 1,65 & STT & 1480 & 55 & 0 & $100 \%$ \\
\hline 6 & 1,5 & 1,65 & TT & 670 & 65 & 1 & $98 \%$ \\
\hline 6 & 1,5 & 1,65 & STT & 675 & 28 & 0 & $100 \%$ \\
\hline 6 & 1,5 & 1,65 & TT & 39 & 9 & 0 & $100 \%$ \\
\hline 6 & 1,5 & 1,65 & STT & 3675 & 149 & 0 & $100 \%$ \\
\hline 6 & 1,8 & 2,00 & TT & 1470 & 50 & 0 & $100 \%$ \\
\hline 8 & 1,5 & 2,00 & STT & 1400 & 62 & 0 & $100 \%$ \\
\hline 8 & 1,5 & 2,00 & TT & 90 & 3 & 0 & $100 \%$ \\
\hline 8 & 1,5 & 2,00 & TT & 1400 & 82 & 2 & $98 \%$ \\
\hline 8 & 1,8 & 2,00 & STT & 1550 & 83 & 2 & $98 \%$ \\
\hline 8 & 1,8 & 2,00 & STT & 1965 & 53 & 1 & $98 \%$ \\
\hline 8 & 1,8 & 2,00 & $\begin{array}{l}\text { STT } \\
\end{array}$ & 970 & 56 & 2 & $96 \%$ \\
\hline 8 & 1,8 & 2,00 & $\begin{array}{l}\text { STT } \\
\end{array}$ & 1870 & 102 & 5 & $95 \%$ \\
\hline 8 & 1,8 & 2,00 & STT & 885 & 34 & 3 & $91 \%$ \\
\hline 8 & 1,8 & 2,00 & STT & 1580 & 83 & 6 & $93 \%$ \\
\hline 8 & 1,8 & 2,00 & STT & 1900 & 101 & 2 & $98 \%$ \\
\hline 8 & 1,8 & 2,00 & $\begin{array}{l}\text { STT } \\
\end{array}$ & 690 & 91 & 4 & $96 \%$ \\
\hline 8 & 1,8 & 2,00 & STT & 975 & 19 & 1 & $95 \%$ \\
\hline 8 & 1,8 & 2,00 & STT & 1000 & 53 & 3 & $94 \%$ \\
\hline 8 & 1,8 & 2,00 & $\begin{array}{l}\text { STT } \\
\end{array}$ & 1000 & 61 & 0 & $100 \%$ \\
\hline 8 & 1,8 & 2,00 & STT & 900 & 57 & 2 & $96 \%$ \\
\hline 8 & 1,8 & 2,00 & STT & 1000 & 3 & 0 & $100 \%$ \\
\hline 8 & 1,8 & 2,00 & STT & 1215 & 65 & 4 & $94 \%$ \\
\hline 8 & 1,8 & 2,00 & $\begin{array}{l}\text { STT } \\
\end{array}$ & 1445 & 79 & 3 & $96 \%$ \\
\hline 8 & 1,8 & 2,00 & TT & 1040 & 54 & 0 & $100 \%$ \\
\hline 8 & 1,8 & 2,00 & TT & 1270 & 73 & 2 & $97 \%$ \\
\hline 8 & 1,8 & 2,00 & TT & 1700 & 88 & 1 & $99 \%$ \\
\hline 8 & 1,8 & 2,00 & TT & 1295 & 70 & 1 & $99 \%$ \\
\hline 8 & 1,8 & 2,00 & TT & 900 & 50 & 1 & $98 \%$ \\
\hline 8 & 1,8 & 2,00 & TT & 1590 & 87 & 1 & $99 \%$ \\
\hline 10 & 1,8 & 2,00 & $\begin{array}{l}\text { STT } \\
\end{array}$ & 776 & 50 & 0 & $100 \%$ \\
\hline 10 & 1,8 & 2,00 & STT & 608 & 40 & 0 & $100 \%$ \\
\hline 10 & 1,8 & 2,00 & $\begin{array}{l}\text { STT } \\
\end{array}$ & 1204 & 82 & 1 & $99 \%$ \\
\hline 10 & 1,8 & 2,00 & STT & 1314 & 86 & 0 & $100 \%$ \\
\hline
\end{tabular}



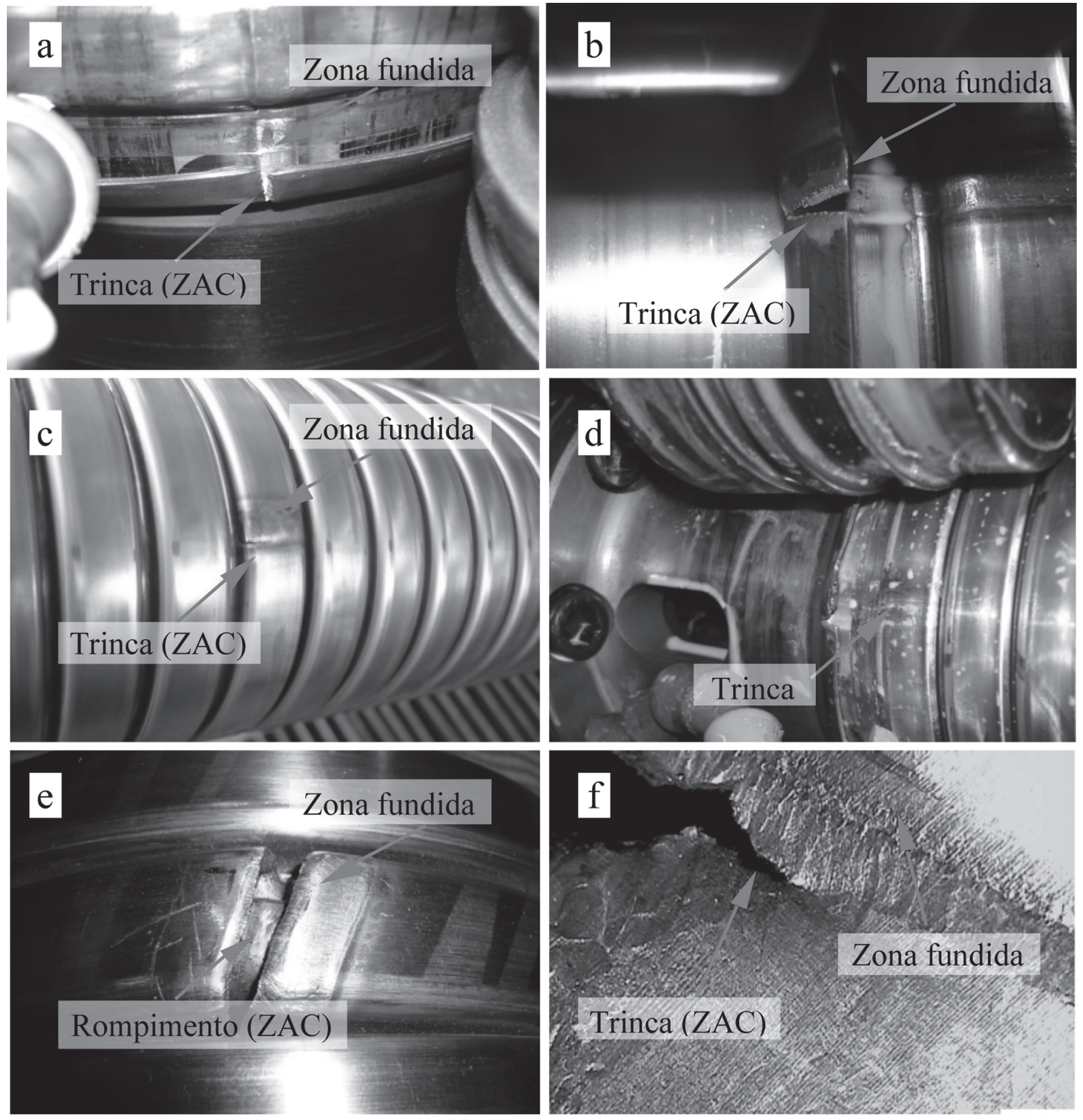

Figura 5. Aspecto visual das trincas durante a conformação mecânica e após: diâmetro de 8", Material 1(a); diâmetro de 8", Material 2(b); diâmetro de 4", Material 1 (c); diâmetro de 4", Material 2(d); detalhe de trinca em diâmetro de 8", Material 1(e); visualização de (e) em estereomicroscópio (f) 
Tabela 4. Resultado da interação entre os fatores na análise de variância

\begin{tabular}{|l|c|}
\hline & $\mathrm{p}$ \\
\hline Tipo de material fornecido (1) & 0,004202 \\
\hline Diâmetro da tubulação (2) & 0,000045 \\
\hline Interação (1 x 2) & 0,002791 \\
\hline
\end{tabular}

\begin{tabular}{|l|c|}
\hline & $\mathrm{p}$ \\
\hline Tipo de material fornecido (1) & 0,150573 \\
\hline Espessura da tubulação (2) & 0,021307 \\
\hline Interação (1 x 2) & 0,049745 \\
\hline
\end{tabular}

\begin{tabular}{|l|c|}
\hline & $\mathrm{p}$ \\
\hline Tipo de material fornecido (1) & 0,051363 \\
\hline Tratamento térmico (2) & 0,170664 \\
\hline Interação (1 x 2) & 0,293953 \\
\hline
\end{tabular}

\begin{tabular}{|l|c|}
\hline & $\mathrm{p}$ \\
\hline Tratamento térmico (1) & 0,632176 \\
\hline Espessura da tubulação (2) & 0,238109 \\
\hline Interação (1 x 2) & 0,644444 \\
\hline
\end{tabular}
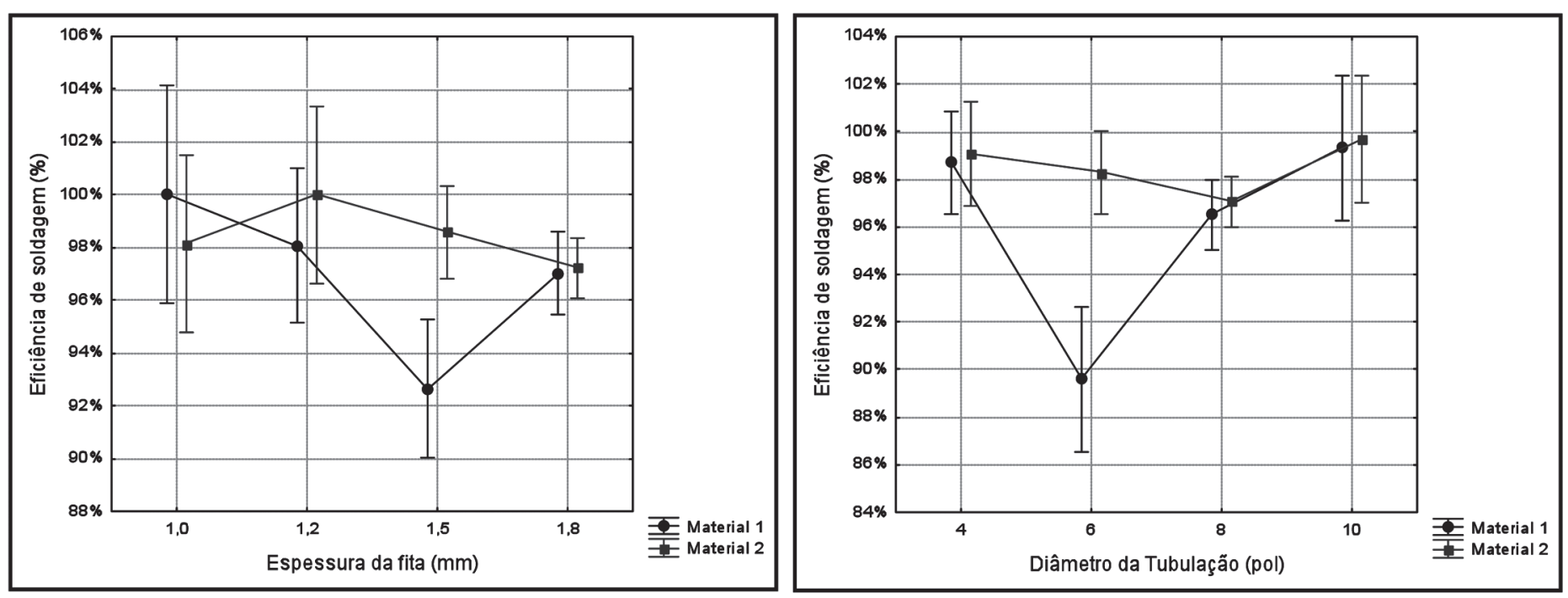

Figura 6. (a)Avaliação da eficiência de soldagem em termos do tipo de material e das espessuras das fitas utilizadas; (b)Gráfico da eficiência de soldagem, com distinção de fornecedores, para diferentes diâmetros de tubulação produzida.

Os dados foram avaliados em quatro níveis, sendo observado com mais intensidade o efeito do tipo de material, espessura deste e o diâmetro da tubulação gerada a partir desse material. A Tabela 4 retrata a análise dos dados mostrando o efeito desses fatores e o efeito da interação entre eles. Observando esses dados, verifica-se que o fator mais influente na eficiência de soldagem, abordado no trabalho, foi o tipo de material utilizado para a fabricação dos dutos. Observa-se, que quando se muda o Material 1 para o Material 2, essa eficiência é elevada.

É observada uma variação da eficiência de soldagem quando se aumenta a espessura das fitas e também o diâmetro das tubulações a serem conformadas. Comparando as Figuras 6a e $6 \mathrm{~b}$, nota-se uma depressão no índice de eficiência de soldagem. Quando se observa as Tabelas 2 e 3, nota-se que as espessuras inferiores a 1,5 mm das fitas utilizadas na produção das carcaças dos tubos flexíveis são utilizadas para a conformação de tubos inferiores a 6". Observa-se ainda que a maior incidência de trincas acontece para essa espessura de fita e esse diâmetro de tubulação (1,5mm e 6" respectivamente). No entanto tal efeito é pronunciado apenas no Material 1.

Através da análise de variância das espessuras das fitas utilizadas, verifica-se que há uma grande dispersão nos resultados de eficiência de soldagem em relação à espessura das chapas utilizadas na conformação mecânica dos tubos. Essa dispersão se minimiza com o aumento da espessura do material utilizado. Em uma avaliação mais criteriosa, nota-se que o Material 1 tem maiores dificuldades de manter a eficiência de soldagem quando se tem espessuras maiores. Isso é mais pronunciado quando se observa espessura de $1,5 \mathrm{~mm}$. A princípio sua eficiência só é maior para espessuras menores (Figura 6a).

Quando se observa a Tabela 2 (Material 1), nota-se que os números de trincas sem o tratamento térmico são superiores para o diâmetro de 6" e espessura de $1,5 \mathrm{~mm}$ da fita utilizada, se comparadas à Tabela 3 (Material 2). Acredita-se que tal efeito seja resultado da composição química diferenciada apresentada por esses dois materiais. Embora ambos estejam dentro das faixas aceitáveis para a classe de aço citada (UNS S32304), ocorrem variações químicas, como citado anteriormente, que podem interferir nos resultados, tanto de resistência quanto de tenacidade. Esse efeito pode ser mais pronunciado quando se observa a geometria dos tubos a serem conformados, o que irá definir a severidade de deformação mecânica. No caso específico do teor de níquel, além de proporcionar uma maior resistência mecânica, tenacidade, atua como elemento austenitizante [14]. A princípio, em função desse maior teor de Ni no Material 1, supunha-se que esse material fosse menos 

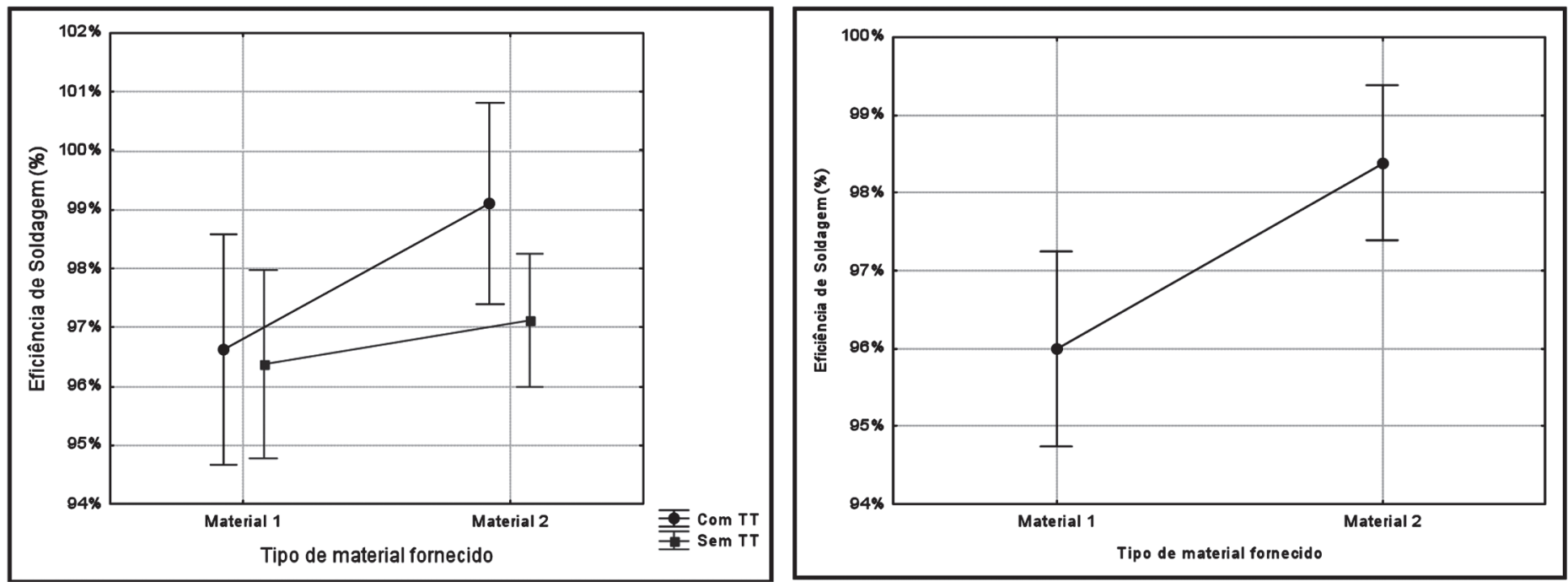

Figura 7. (a) Avaliação da eficiência de soldagem em termos do tratamento térmico e o tipo de material soldado; (b) Avaliação da eficiência de soldagem em termos do tipo de material fornecido.

susceptível ao efeito do ciclo térmico de soldagem. No entanto, observa-se nesse mesmo material teores mais elevados de Si e Mo. Em particular, o silício em teores elevados podem fragilizar o material. A literatura afirma que tal elemento também atua na termodinâmica de formação da ferrita [16]. Segundo o estudo de Miller et alli [14], o aumento no teor de níquel promoveria a ativação da decomposição espinodal da ferrita que poderia gerar modificações nas características mecânicas da liga. Os estudos de Brown et alli [20] já apontavam a influência do níquel, molibdênio e silício em efeitos de envelhecimento de algumas ligas $\mathrm{Fe}-\mathrm{Cr}$.

Acredita-se que a espessura do material interfira diretamente no sistema de dissipação térmica, influindo diretamente nos fenômenos metalúrgicos durante a soldagem. Devido aos níveis de solicitação no processo de conformação e aos processos térmicos, alguns sistemas, no que se refere a precipitação ou variação metalúrgica, possam ter sido ativados. Para essa espessura em particular, há uma variação de aporte de energia $(1,65 \mathrm{~kJ} / \mathrm{mm}$ - Tabelas 1 e 2$)$ em relação às demais espessuras, logo, o efeito desse aporte de energia pode ter uma influência mais pronunciada, uma vez que pelas equações de Rosenthal [19], em todos os casos apresentados, ter-se-ia um sistema bidimensional de dissipação de calor, o que leva a dissipação térmica mais tênue para condições de baixa espessura da junta soldada.

Assim, devido aos valores diferenciados de níquel, molibdênio e silício e a possível tendência de fragilização de regiões que tenham sofrido variações térmicas, como é o caso da $\mathrm{ZAC}$ e regiões adjacentes à região fundida, pontos preferenciais de fratura (Figura 5), atrelado ao sistema térmico sofrido por tal material, o efeito da minoração das características mecânicas se torna mais pronunciado.

$\mathrm{O}$ resultado mostrado nessa parcela do material aponta para um efeito térmico sobre o material, podendo ser o procedimento de soldagem um dos fatores para esse resultado particular das falhas. E possível que uma variação paramétrica na soldagem da liga em questão possa a minimizar os efeitos da conformação mecânica. Levando em consideração a particularidade do sistema bidimensional do fluxo de calor, a energia a ser aplicada ao processo deverá estar em consonância com o volume da junta a ser soldada. No caso das juntas de menor volume $(1,0$ $\mathrm{mm}$ e $1,2 \mathrm{~mm}$ ) esse efeito não é perceptível, pois a diferença volumétrica de material é pequena, mantendo, teoricamente um fluxo de calor similar. Assim, acredita-se que ajustes no aporte de calor possa modificar os efeitos observados para o Material 1, equalizando o seu desempenho.

Em uma avaliação secundária, nota-se que o efeito do tratamento térmico não é pronunciado no que tange à eficiência de soldagem estabelecida. Pela análise estatística da Tabela 4, os dados mostram que a mesma não tem influência signicativa. Observando a Figura 7a observa-se que esse efeito é bem tênue, só se mostrando variante para o Material 2. Isso vem a reafirmar a infuência do material sobre essa eficiência de soldagem.

De acordo com a literatura, esperava-se que houvesse uma mudança significativa nos índices de falhas com a utilização do procedimento de tratamento térmico pós soldagem, uma vez que tal procedimento permitiria a dissociação de algum componente fragilizante, gerado durante o ciclo térmico de soldagem. Ao observar os dados é verificado que tal procedimento não interfere diretamente nas falhas geradas. Quando se isola o Material 2 na análise, é verificado que o mesmo apresenta melhor aspecto em termos da eficiência de soldagem (Figura 7 b). Mesmo com uma melhor característica no que se refere a ausência de falhas durante o processo de fabricação das tubulações, é notado que o mesmo aumenta a sua eficiência com a inserção do tratamento térmico durante o processo.

Esse efeito pode ser resultado do balanço composicional da liga, que possibilita uma manutenção das carcaterísticas mecânicas da mesma, mesmo que esta seja submetida a um processo térmico, como o caso da soldagem. 


\section{Conclusões}

O Material 2 se mostrou mais estável e com melhores índices em termos das falhas ocorridas após a soldagem das fitas metálicas paraa produção da carcaça de tubuos flexívies;

$\mathrm{O}$ tratamento térmico executado após a soldagem das fitas para a composição da carcaça dos tubos flexíveis, fabricados com o aço aço inoxidável duplex UNS S32304, não apresenta interferência significativa quando avaliados todos os materiais;

Existe um efeito particular para o Material 1, podendo ser resultado do aporte térmico insuficiente para o volume de material da junta;

O Material 2, quando submetido ao tratamento pós soldagem melhora o seu comportamento em relação as falhas durante o processo de conformação mecânica das fitas metálicas soldadas.

\section{Agradecimentos}

Os autores agradecem à TECHNIP, à ANP e a UFES pelo apoio e material para se estabelecer tal estudo.

\section{Referências Bibliográficas}

[1] WITZ, J. A.: A Case Study in the Cross-section Analysis of Flexible Risers. Marine Structures, 9 (1996), pp. 885-904

[2] TAVARES, S.S.M.; SCANDIAN, C.; PARDAL, J.M.; LUZ, T.S.; SILVA, F.J.: Failure analysis of duplex stainless steel weld used in flexible pipes in off shore oil production, Engineering Failure Analysis. 17 (2010), pp.1500-1506.

[3] J. MICHALSKA; M. SOZANSKA, Qualitative and quantitative analysis of $\sigma$ and $\chi$ phases in 2205 duplex stainless steels, Mater. Charact. 56 (2006), pp. 355-362.

[4] SATO Y. S.; KOKAWA, H.: Preferential precipitation sit of sigma phase in duplex stainless steel weld metal, ScriptaMaterialia, 40-6(1999), 659-663.

[5] GREGORI, A.; NILSSON, J. O.; BONOLLO, F.: Quantitative assessment of intermetallic phase precipitation in a superduplex stainless steel weld metal using automatic image analysis, Materials Science Forum, Trans. Tech. Publications, Svizzera,(1999), 829-834.

[6] NAKADE, K.:Sigma phase precipitation and its influence on hydrogen induced cracking of duplex stainless steel base metal and weld metal. Welding in the World. Vol. 47, (2003),9-20, $\mathrm{N}^{\circ}$ 9/10.

[7] POHL, M.; STORZ, O.; GLOGOWSKI, T.: Effect of intermetallic precipitations on the of duplex stainless steel. Materials Characterization, [S.1.], v. 58, (2007), p. 65-71.

[8] SIEURIN H., ZANDER J., SANDSTRÖM R., Modelling solid solution hardening in stainless steels, Materials Science and Engineering A. vol. 415, (2006), pp. 66-71.

[9] VAZ, M.A.; RIZZO, N.A.S.: A finite element model for flexible pipe armor wire instability. Marine Structures, in press, (2011), pp. 1-17.

[10] KLIAUGA, A. M.; POHL, M.: Effect of plasma nitriding on wear and pitting corrosion resistance of X2 CrNiMoN 22 53 duplex stainless steel, Surface and Coatings Technology, Volume 98, Issues 1-3, (1998), pp 1205-1210.
[11] CHEN, L.; TAN, H.; WANG, Z. ; LI, J.; Y. JIANG.: Influence of cooling rate on microstructure evolution and pitting corrosion resistance in the simulated heat-affected zone of 2304 duplex stainless steels. CorrosionScience 58, (2012), 168-174. [12] CARVALHO, S. M.; NACARI, L. F.; LUZ, T. S.; ASSUNÇÃO, D.: Evolução da microestrutura da soldagem autógena do aço UNS31803 com tratamento pós soldagem. $65^{\circ}$ Congressoda ABM, (2010).

[13] SIEURIN, H.; WESTIN, E. M.; LILJAS, M.: Fracture toughness of welded commercial lean duplex stainless steels. Welding in the World, 53, (2009), pp. R24-R33.

[14] MILlER, M. K.; ANDERSON, L. M.; BENTLEY, J.; RUSSELL, K. F.: Phase separation in the Fe-Cr-Ni system. Applied Surface Science 94/95, (1996), 391-397.

[15] MUNDT R., HOFFMEISTER H.: The isothermal $\delta-\gamma$ transformation of ferrite-austenitic iron- chromium-nickel alloys, Hansburg, Arch Eisenhuttenwes 54, N. 7, (1983), pp. 291-294.

[16] LIPPOLD, J.C.; KOTECKI, D.J. Welding metallurgy and weldability of stainless steels. John Wiley \& Sons, Inc, 2005.

[17] SIEURIN, H.; SANDSTRÖM, R.: Sigma phase precipitation in duplex stainless steel 2205. Materials Science and Engineering A 444, (2007), pp. 271-276.

[18] BHADESHIA,H. K. D. H.; HONEYCOMBE, R.: Steels - Microstructure and Properties. Third edition, ButterworthHeinemann, Elsevier, 2006.

[19] KOU, S.: Welding Metallurgy. John Wiley \& Sons, 2nd ed. USA, 2003.

[20] BROWN, J. E. AND SMITH, G. D. W.: Atom probe studies of spinodal processes in duplex stainless steels and single and dual-phase Fe-Cr-Ni alloys. Surface Science 246,(1991), pp. 285-291. 